\title{
Italian Astronomers in the IAU: the contribution and role of Italian astronomers from the foundation to the Second World War
}

\author{
V. Zanini ${ }^{1}$, M. Gargano ${ }^{2}$ and A. Gasperini ${ }^{3}$ \\ ${ }^{1}$ INAF - Astronomical Observatory of Padova Vicolo dell'Osservatorio, 5-35122 Padova, Italy \\ email: valeria.zanini@inaf.it \\ ${ }^{2}$ INAF - Astronomical Observatory of Capodimonte Salita Moiariello, 16-80131 Napoli, Italy \\ email: mauro.gargano@inaf.it \\ ${ }^{3}$ INAF - Astrophysical Observatory of Arcetri Largo Enrico Fermi, 5-50125 Firenze, Italy \\ email: antonella.gasperini@inaf.it
}

\begin{abstract}
Even though Italy officially joined the IAU in 1921, Italian astronomers were involved in its birth as early as 1919, when Annibale Riccò, Director of the Astrophysical Observatory of Catania, proposed to the IAU Committee to hold its first General Assembly in Rome. This contribution will analyze the role played by Italian astronomers in the development of the IAU from its foundation to the Second World War. The recent project of reordering of the astronomical historical archives in Italy permits for the first time a more in-depth study of the relations between Italian astronomers and the international scientific community.
\end{abstract}

Keywords. History of IAU, first General Assembly, Italian astronomers

\section{Towards the 1919 Brussels Conference}

The International Astronomical Union was born during the Constitutive Assembly of the International Research Council (IRC) held from July 18 to 28, 1919, in Brussels, with the aim "to facilitate the relations between astronomers of different countries where international co-operation is necessary or useful" and "to promote the study of astronomy in all its departments" (Fowler 1922a, p. 3).

Organized by the Allies after the end of the World War I, the Brussels meeting was the third Inter-allied Conference on international scientific organizations. The first two were held in London, October 9-11, 1918, during the war, and in Paris, from November 26th to 29th, a few days after the armistice.

These Conferences were the result of an intense activity made by the Allied scientists during the war years, to entirely re-assess international scientific relationships, and decreed the "end of prewar cosmopolitanism and the consequent dissolution of the International Association of Academies (AIA)" (Linguerri 2015a, p. 84).

The representatives of Belgium, Brazil, France, Great Britain, Japan, Italy, Portugal, Serbia and the United States of America in London, declared on October 1918:

"If to-day the representatives of the scientific academies of the Allied nations are forced to declare that they will not be able to resume personal relations in scientific matters with their enemies until the Central Powers can be readmitted into concert of civilized nations, they do so with a full sense of responsibility; and they feel bound to record the reasons which have led them to this decision... In order to restore 
the confidence, without which no scientific intercourse can be fruitful, the Central Powers must renounce the political methods which have led to the atrocities that have shocked the civilized world" (The Observatory 1918, p. 415).

Among the signatories there was also Vito Volterra, the Italian scientist, who had previously participated to the private meeting held in London in the Spring, together with some delegates of the Royal Society, the Paris Académie des Sciences and the Accademia dei Lincei in Rome. The creation process of the IRC started from these "private preparatory conversations", integrated with the proposal of the American astronomer George E. Hale (1868-1938) "about the constitution in the various Allied countries of a national research council, including those referring to the national defense, similar to the one already working in the United States" (Volterra 1918a, p. 276).

Vito Volterra (1860-1940), a famous mathematician, was born into a humble Jewish family; at the beginning of 1900 he was professor of mathematical physics at the University of Rome La Sapienza and he was a highly respected scientist in Italy and abroad, as witnessed by the impressive correspondence of 16000 letters exchanged with 1500 correspondents, all around the world, preserved at the Accademia dei Lincei. He was also an important political figure; in 1905 he was nominated Senator of the Kingdom of Italy and involved "in the creation of many scientific institutions, so that Italy could play a major role in world science" (Mazliak \& Tazzioli 2009, p. 10). In 1897, in fact, Volterra founded the Italian Physical Society and in 1907 he created the Italian Society for the Progress of Science, inspired by analogous French and British organizations and devoted to the advancement and popularization of science. When Italy entered the First World War, the 55-year-old Volterra enrolled as a volunteer, taking care of technical and scientific problems like ballistic issues, aircraft artillery and helium supplies for airships. In 1917, inspired by the foreign colleagues and by the war experience, Volterra created the 'Invention and Research Office' to use technological knowledge for military purposes; his aim was to put Italy on the same level as the other scientifically advanced countries.

During the first Inter-allied Conference in London, a provisional Commission (the first IRC executive commission, then confirmed at Paris and Brussels) was charged to formulate "a general plan of international organizations for needs of different branches of scientific and industrial researches" (Volterra 1918a, p. 278). Volterra himself insisted on the necessity that "this Commission should take immediate resolutions on international geodetic and astronomical studies which, by nature, cannot be interrupted or delayed" (Volterra 1918a, p. 279).

So, during the second Inter-allied Conference in Paris, it was formally "established, under the name of the Astronomical Union, an international association whose aim is the general progress of astronomy and related sciences and arts" (Volterra 1919a, p. 93). In Paris the first IAU Executive Commission was also established and it was composed of the President Benjamin Baillaud (1848-1934), the General Secretary Alfred Fowler (1868-1940) and four Vice-presidents: the American, William Campbell (1862-1938), the Briton, Frank Dyson (1868-1939), the Belgian, Georges Lecointe (1869-1929) and the Italian, Annibale Riccò (1844-1919).

The Executive Commission "proposed the agenda for the first IAU Constitutive Assembly, which will take place as soon as circumstances permit and possibly coincide with the meetings of the Constitutive General Assembly of the International Geophysical Union" (Volterra 1919a, p. 99), which was also formally established at the Paris conference. Those 'circumstances' materialized in the third Inter-allied Conference, which generated the IRC and officially established the IAU, which was born exactly with the restored peace in Europe. 


\section{Italian IAU membership}

The inter-allied nations constituted the founding nucleus of the IAU, even though Italy was not formally included among them, as can be seen from the letter Alfred Fowler sent to the Directors of the Italian Observatories in July 1920:

"The General Secretary presents his compliments to the members of the International Astronomical Union and has pleasure in informing them that the conditions laid down at the Brussels Conference for the formal constitution of the Union have been fulfilled.

The countries which have definitely signified their adherence to the Union are Belgium, Canada, France, Greece, Japan, the United Kingdom and the United States. In addition, it is understood that steps towards joining the Union have been taken by Australia, Italy and South Africa" (Fowler 1920a,b).

If Italy was actually a de facto IAU member from the beginnings, why does Fowler talk about it as a later associate member? The reason can be found partly in the lack of a national body - the national Committee - which, according to IAU rules, had to be the link between Italian astronomers and IAU. Furthermore, on September 23, 1919, Annibale Riccò died suddenly, followed on December 5 by the passing away of Elia Millosevich (1848-1919), Director of the Observatory of the Collegio Romano and Riccò's successor in the IAU Executive Commission. Therefore, an active Italian participation was missing for several months, until Antonio Abetti (1846-1928), the dean of Italian astronomers and Director of Arcetri Observatory, was appointed as IAU vice-president. But the primary reason was that the formal IAU membership was subjected to payment of an annual fee of 12000 francs, which was not yet paid by Italy in July 1920.

In the meantime, Italian astronomers decided to rearrange the Società degli Spettroscopisti Italiani, the first international society devoted to solar and stellar physics research (Zanini \& Zaggia 2016), into the Italian Astronomical Society. This was formally established on January 7, 1920 at the Accademia dei Lincei. Its newly appointed Organizing Committee was composed of Vincenzo Cerulli (1859-1927), founder of the Astronomical Observatory of Teramo, who was elected as President, Azeglio Bemporad (1875-1945), Director of the Astronomical Observatory of Capodimonte (Naples), Emilio Bianchi (1875-1941), the new director of the Observatory of the Collegio Romano following premature death of Millosevich, the physicist Antonio Garbasso (1871-1933) and Vito Volterra, the real driving force behind the Italian participation in the new international scientific arena in that period.

During the Brussels Conference, Annibale Riccò proposed to hold the first IAU General Assembly (GA) in Rome, together with the first GA of the International Geophysical Union. All the astronomers assembled accepted the proposal zestfully. The upcoming international meeting urgently needed at least a national 'Authorizing Committee' to provide for the arrangement. Due to the lack of a National Research Council, which would be formally established only in 1923, Volterra founded a 'temporary' astronomical Committee during the establishment of the new Italian Astronomical Society. The Comitato nazionale italiano astronomico - the National Astronomical Committee was the official body to represent "Italy within the International Astronomical Union" (Statuto del Comitato Nazionale Astronomico 1921). This Committee would also coordinate the complex activities to organize the GA.

The Board was officially announced during the first meeting (Rome, May 8-9, 1921) of this national astronomical Committee, and it was just the entire Organizing Committee of the new Astronomical Society. Inside the Board, Emilio Bianchi was appointed as Secretary. 
The organization of the 1922 joint (Astronomical and Geophysical) GA was finally operational; the Board estimated a cost of 100000 lire (about 100000 present-day euros) and addressed an economic request to the Italian Government, the Foreign Affairs and Economy Ministries. Thanks to Volterra, the Accademia dei Lincei offered its headquarters as a venue for the two GAs, starting from April 20, 1922 (Statuto del Comitato Nazionale Astronomico 1921).

However, Italy still had the unsolved problem of paying the IAU membership fee either for the past year 1920 or for the current year, as Fowler himself wrote to the Secretary of the national Committee, Emilio Bianchi:

"I have been reminded by $M$. Baillaud the position of Italy in relation to the International Astronomical Union is somewhat anomalous. From the formation of the Union, it has, of course, been assumed that it was the intention of Italy to join; and to contribute to the funds in accordance with the scheme agreed upon at Brussels.

No doubt the delay in forming the National Committee has been unavoidable, and accounts for the delay in the formal adherence of Italy to the Union.

I should be greatly obliged if you would be good enough to inform me if steps have now been taken towards joining the Union, and whether the subscription for the year 1920 as well as for the current year may be expected" (Fowler 1921a).

So the Board used a part of the Public Education Ministry funds to regulate the 1920 subscription. On August 9, 1921, President Baillaud received from Italy the bank check for 12000 francs, around 19500 euros. The following month, finally, Fowler communicated to Antonio Abetti the formal membership of Italy to the IAU (Fowler 1921b):

Imperial College London S. W. 7 16th September 1921

Dear Professor Abetti,

No doubt you have already been informed that Italy has now formally adhered to the I.A.U., and that, on behalf of the Executive Committee, Monsieur Baillaud has accepted the invitation to hold the General Assembly of the Union in Rome on April 20th 1922...

With kindest regards, Yours sincerely, fto. A. Fowler

\section{The first General Assembly: Rome 1922}

In the following months Italian astronomers had a heated debate to provide the GA with an efficient local organization and fruitful scientific contributions. The scientific work of the IAU would be carried on by Standing Committees, on the basis of a proposal of the National Committees related to this topic. Giorgio Abetti (1882-1992) proposed that IAU Commission 12 De l'atmosphère solaire should discuss about "the best instruments for a comparative study of solar and terrestrial phenomena, taking into account a systematic measure of the 'discharges' or 'intruders' that rotate in wireless telegraphic signals", in partnership with the Meteorological and Magnetism and terrestrial electricity Sections of the Geophysical Union. Commission 24 Des parallaxes stellaires, instead, would have to split the work of trigonometric and spectroscopic stellar parallaxes among various observatories. Furthermore, Abetti recommended Italy's participation in the work of the radiotelegraphic determination of the longitudes around the Earth. He trusted that the proposal would be discussed by Commission 18 Des longitudes par télégraphie sans fil, together with the Geodetic Section of the Geophysical Union (Cerulli 1921). Finally, Bianchi asked Commission 20 Des Petites planètes to observe "regularly and 
systematically" (Fowler 1922a, p. 167) little planets whose light was supposed to vary and, together with his colleague Luigi Volta (1876-1952), highlighted the need to modify the international latitude programme of Kimura, inside Commission 19 De la variation des latitudes (Kimura 1902). The Italian Astronomical Committee was also the only one to send a proposal for Commission 1 De la relativité: to verify the relativistic theory in the gravitational field of Jupiter by analyzing stellar movement near the planet's disk and studying the apsidal motion of its 5th satellite, Amalthea.

Meanwhile, also the international contacts carried on, especially with Emilio Bianchi, Secretary of the National Committee - who was going to become the new Director of the Brera Observatory in Milan. Fowler and Bianchi had to postpone the conference date from April to May, because of a concomitant "conference of Railway people" (Fowler 1921c) concerning the International Geophysical Union. Thus the meeting was scheduled for May 2-10, 1922. Finally, Alfred Fowler asked Antonio Abetti to prepare the meeting programme:

"One of the main points is that the programme of the meeting must be prepared at least four months in advance of the meeting, so that National Committees will be requested to inform us before the first of November of any questions which they wish to be presented for the discussion" (Fowler 1921b).

The scientific programme was discussed by Fowler especially with Giorgio Abetti, son of Antonio, who was the main reference in Italy for the British and American astronomers, thanks to his astronomical training spent in the USA. In January 1922 Fowler informed Abetti that the agenda was still to be defined, because the proposals of American astronomers were late. Anyway, in March the programme was then outlined and approved by Fowler: "The programme is very interesting, and I think we shall all be pleased with the arrangements which have been made by our Italian colleagues" (Fowler 1922b).

At the beginning of 1922, however, the problem of the annual Italian fee came back again, because the Government had not paid the 20000 lire for 1921 and there was no guarantee to comply with international agreements for the following decade. The National Astronomical Committee obtained by the Ministry only one half of the sum, so the Board proposed to cover the remaining 10000 lire with funds provided directly by the Observatories. On March 27, 1922, Bianchi was then forced to ask the Directors of the Italian Observatories to contribute to this amount proportionally to their own annual budgets. The request caused great dissatisfaction among Italian Directors, who were already struggling with a persistent structural shortage of funds for research, but almost no-one pulled back or withdrew. As the Director of the Turin Observatory, Giovanni Boccardi (1859-1936), wrote: "the honour of our Country is at stake here, and it's good not publicize its miseries abroad" (Boccardi 1922). Eventually, the fundraising made possible to pay the registration fee for 1921 and to avoid the danger for Italy to host the first IAU GA without being officially a member for not complying with the registration fee.

Despite all the political and economic difficulties, the conference finally started. On May 2, 1922 the Inaugural Ceremony took place in the Great Hall of the Orazi and Curiazi in the Campidoglio in the presence of the King of Italy, Vittorio Emanuele III, with the welcome address of Vito Volterra. The opening meeting of the General Assembly was held at the Accademia dei Lincei on May 3, under the presidency of Baillaud. Vincenzo Cerulli, on behalf of the local Committee of Italian Astronomers, welcomed the Union to Rome reading the inaugural speech (Fowler 1922a, p. 145).

Thirty-two Standing Committees were engaged in discussing international astronomical work during the meeting, according to the previously agreed programme. The Italian astronomers attended eighteen of them, even though only Cerulli covered the Presidential position in Commission 16 Observations physiques des planètes et des satellites. 


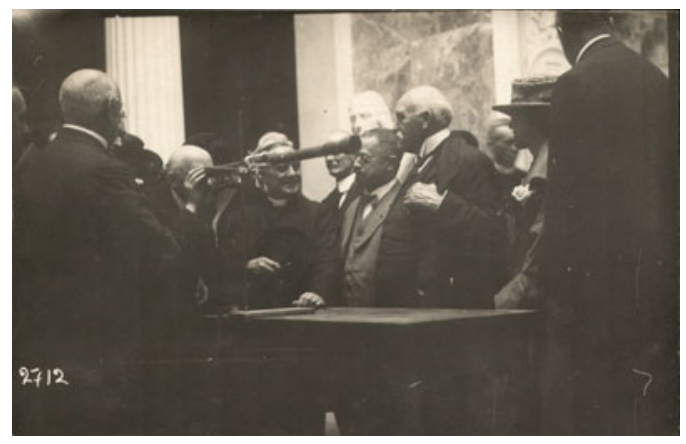

Figure 1. Astronomers from all over the world look through Galileo's telescope (Arcetri Astrophysical Observtory).

In particular, inside Commission 10 Radiation solaire, Azeglio Bemporad proposed to set up a pyrheliometric station in Capri, while within Commission 12 Atmosphère solaire the role of Italy in the observation and study of prominences was finally recognized:

"As for the statistics of prominences, it is well known that these have been published regularly by the Italian observers since the time of Secchi. It is desiderable that this work should be continued under the general direction of Dr. Abetti, who has succeeded the late Professor Riccò as a member of this Committee, and is devoting his chief attention to solar research in Arcetri" (Fowler 1922a, p. 32).

The only sore point for Italy was the non-participation of the Catania Observatory in the work of Commission 23 Carte du Ciel, considering that the contribution from Catania represented "about one-tenth of the whole work". Unfortunately, there was not a worthy successor of Riccò to the direction of the Astrophysical Observatory of Catania and to the guidance of the international catalogue project:

"After the death of M. Riccò no new Director has been formally appointed and no one has assumed the responsibility of sending a report" (Fowler 1922a, p. 62).

Nevertheless, it is recognized that in the following years only the Catania and Helsinki Observatories completed the star catalogues assigned to them in equatorial coordinates. The whole project, not finished, was then abandoned and Commission 23 was finally abolished in 1970.

The first IAU GA also included some social events and post-conference excursions. Among these, we remember a tour to Florence on May 12. The Florentine excursion was a tight schedule of meetings and visits, including the last home of Galileo (Villa Il Gioiello), the Astrophysical Observatory and the Institute of Physics on the Arcetri hill. The most exciting experience was certainly the visit to the Specola, where astronomers from all over the world held Galileo's telescope in their hands, as documented by some photographs preserved in the historical archive of the Arcetri Observatory (Fig. 1). The memory of this day, a journey throughout science, art and nature, was commemorated by Giorgio Abetti with a celebrative scroll, in Florentine flowery style, signed by participants. It was a twice-memorable day, because in 1922 the fiftieth anniversary of the Arcetri Observatory foundation also occurred.

\section{Conclusions}

We cannot forget that while the first IAU GA was taking place, Italy faced a difficult period of political instability and intense social unrest, which eventually led a few months later to the March on Rome (October 1922) and the takeover of the Fascist party. 
Mussolini's rise to power occurred at a time of illegality that a weak State and continuous government changes were not able to prevent. In the following twenty years Italy was then drawn into the tragic Fascist maelstrom that peaked in the criminal racial laws promulgated by Mussolini between September and November 1938, and accepted by most of the Italian middle class. In addition to tens of thousands of innocent citizens, hundreds of scientists were victims of this racist policy, passively received by almost the entire Italian academic world. Volterra himself, chief actor in the Italian internationalization of science, fell victim of the Fascism purges. In 1926 Volterra was not renewed either as President of CNR he created in 1923, or as President of the Accademia dei Lincei, because he had signed in 1925 the 'Manifesto of the Anti-Fascist Intellectuals', written by Benedetto Croce. In 1931 he was removed from his office and forced to retire, because he refused to swear allegiance to fascism. Later he was expelled from all the Italian Academies and then hit by the 1938 racial laws. He died in Rome, in almost total isolation, on October 11, 1940.

Italian science and astronomy greatly suffered by the expulsion of Jewish scientists. We quote at least, among astronomers and mathematicians: Guido Horn d'Arturo, Azeglio and Giulio Bemporad, Luigi Jacchia, Tullio Levi-Civita, Federigo Enriques, as well as Volterra himself; for physicists: Bruno Rossi, Emilio Segrè and also Enrico Fermi, who even though not a Jew himself, left Italy to protect his Jewish wife (Bònoli \& Mandrino 2015).

During the Fascist-era, Italian astronomical technology grew up: the Arcetri Solar Tower was completed in 1925, especially thanks to the great skills and international reputation of Giorgio Abetti, the new observatory of Rome was projected in Monte Porzio Catone and in particular in 1942 the Asiago Astrophysical Observatory was established, as an expression of fascist autarchy. It was the biggest telescope in Europe for many years. However, the cultural impoverishment generated by fascist rule soon confined Italy into a marginal role within the IAU and turned it away from almost all international scientific cooperation. Relations between Italian astronomers and scientists worldwide were resumed only after WWII. The second Italian IAU General Assembly, held in 1952 again in Rome, marked a new beginning for Italian astrophysics. But this is another story.

\section{Acknowledgements}

Special thanks to Daniele Galli, Agnese Mandrino, Angela Mangano and Simone Zaggia for their support and collaboration.

\section{References}

Abetti, G. 1949, L'Unione Astronomica Internazionale ed il futuro progresso delle ricerche astronomiche, in Storia dell'Astronomia, Vallecchi, Firenze, pp. 301-310

Blaauw, A. 1994, History of the IAU. The Birth and First Half-Century of the International Astronomical Union, Kluwer Academic Publishers, Dordrecht

Boccardi, G. 1922, Letter to E. Bianchi, Torino, April 2, Historical Archive of the Astronomical Observatory of Brera, Archivio del Comitato italiano nazionale astronomico, B. 1, f. 1

Bònoli, F. \& Mandrino, A. (Eds) 2015, Sotto lo stesso cielo? Le leggi razziali e gli astronomi in Italia, Atti del Convegno, Bologna, 26 gennaio 2015, Giornale di Astronomia, 41 (2), giugno 2015, pp. 1-60

Cerulli, V. 1921, Letter to A. Abetti, Teramo, October 11, Historical Archive of the Astronomical Observatory of Arcetri, Fondo Giorgio Abetti, B. 10, f. 1

CNR 1927, Annuario 1926 (a cura del Segretario Generale), Premiate Officine grafiche Carlo Ferrari, Venezia

Gasperini, A. 2012, La prima Assemblea Generale dell'Unione Astronomica Internazionale in Italia, Maggio 1922: una "gita" fiorentina. Giornale di astronomia, 38 (2), 47-49 
Fowler, A. 1920a, Letter to A. Bemporad, London, July 6, Historical Archive of the Astronomical Observatory of Capodimonte, Attività Scientifica. Corrispondenza Scientifica, B. 1, f. 3

Fowler, A. 1920b, Letter to A. Antoniazzi, London, July 6, Historical Archive of the Astronomical Observatory of Padova, Atti. Riunioni, Congressi, Esposizioni, b. XXV, f. 3

Fowler, A. 1921a, Letter to E. Bianchi, London, May 31, Historical Archive of the Astronomical Observatory of Brera, Archivio del Comitato italiano nazionale astronomico, B. 1, f. 1

Fowler, A. 1921b, Letter to A. Abetti, London, September 16, Historical Archive of the Astronomical Observatory of Brera, Archivio del Comitato italiano nazionale astronomico, B. 1 , f. 1

Fowler, A. 1921c, Letter to E. Bianchi, London, December 21, Historical Archive of the Astronomical Observatory of Brera, Archivio del Comitato italiano nazionale astronomico, B. 1 , f. 1

Fowler, A. (ed.) 1922a, Transactions of the IAU, Vol. 1, 69

Fowler, A. 1922b, Letter to G. Abetti, London, March 29, Historical Archive of the Astronomical Observatory of Arcetri, Fondo Giorgio Abetti, B. 10, f. 1

Guerraggio, A. \& Nastasi, P. 2005, Italian Mathematics Between the Two World Wars, Birkhauser Verlag, Basel Boston Berlin

Kimura, H. 1902, On the existence of a new annual term in the variation of latitude, independent of the components of the pole's motion, Astronomische Nachrichten, 58 (15), 233-240

Linguerri, S. 2015a, La ricerca dalla guerra alla pace, in Esposito, S. (ed.) Atti del XXXV Convegno annuale SISFA, Pavia University Press, Pavia, pp. 83-97

Linguerri, S. 2015b, Vito Volterra al fronte: dall'Ufficio Invenzioni al Consiglio Nazionale delle Ricerche. Lettera Matematica, 92, 58-68

Mazliak, L. \& Tazzioli, R. 2009, Mathematicians at war: Volterra and his French colleagues in World War I, Archimedes: New Studies in the History and Philosophy of Science and Technology, 22, pp. x-194

Statuto del Comitato Nazionale Astronomico [Draft], 1921, Historical Archive of the Astronomical Observatory of Brera, Archivio del Comitato italiano nazionale astronomico

The Observatory 1918, Inter-Allied Conference on International Organisations. The Observatory, 41, 414-416

Volterra, V. 1918a, Comunicazione. Atti dell'Accademia Nazionale dei Lincei. Rendiconti. Classe di scienze fisiche, matematiche e naturali, XXVII, s. V, pp. 276-278

Volterra V. 1918b, La conferenza interalleata sulla organizzazione scientifica. Conferenza di Londra 9-11 ottobre 1918. L'Intesa intellettuale, 1 (4), 218-222

Volterra V. 1918c, La conferenza interalleata sulla organizzazione scientifica. Conferenza di Parigi 26-29 novembre 1918. L'intesa intellettuale, 1 (4), 222-230

Volterra, V. 1919a, Comunicazione. Atti dell'Accademia Nazionale dei Lincei. Rendiconti. Classe di scienze fisiche, matematiche e naturali, XXVIII, s. V, pp. 90-99

Volterra V. 1919b, La Terza Conferenza del Consiglio Internazionale di Ricerche, tenuta a Bruxelles dal 18 al 28 luglio 1919. L'Intesa intellettuale, 2 (3-4), 132-150

Zanini, V. \& Zaggia, S. 2016, An Italian scientific Society for Astrophysics, Chinnici I. (ed.), Starlight: La Nascita dell'Astrofisica in Italia / The Origins of Astrophysics in Italy, Napoli, Arte'm, pp. 104-110 